\title{
VARIATIONS OF THE ARTERIAL SUPPLY OF THE KIDNEY IN MAN: AN ANATOMICAL AND ANGIOGRAPHIC STUDY
}

\author{
By \\ Hoda Mahmoud El-Aasar-Manal Haleem Wahba* \\ Departments of Anatomy and Radiology* \\ Faculty of Medicine - Cairo University
}

\section{INTRODUCTION}

Classically, each kidney is thought to have a single renal artery; however, numerous published studies describe common variations in renal vascular anatomy in which two or more renal arteries supply a kidney (Williams et al., 1995; Ali-El-Dein et al., 2003; Bude et al., 2003; Bordei et al., 2004; Khamanarong et al., 2004). Although frequently described, there is still controversy regarding the naming of these arteries. There were named supplementary by Anderhuber and Weiglein (1992), multiple by Chevrel (1994) and Khamanarong et al. (2004), accessory by Williams et al. (1995) and Goscicka et al. (1996), additional by Satyapal et al. (2001) and aberrant by Vilhova et al (2002). Bordei et al. (2004) named the supplementary arteries entering the renal hilum as proper supplementary arteries while those entering the kidney at the upper and lower polar levels were named superior and inferior polar arteries, respectively. On the other hand, Debatin et al. (1993) named them supernumerary renal arteries and the hilar supernumerary arteries were classified as co-dominant if they were similar in size to the epsilateral main renal artery.

Multiple renal arteries with an aortic origin represent a frequent vascular variation at kidney level, more common than multiple renal veins in a ratio of 1/8 (Bordei et al., 2004). The frequency of multiple renal arteries ranges between $18-36 \%$ and the incidence varies according to the sex and the ethnic origin (Satyapal et al., 2001). Variations in renal vascular anatomy have grown in importance with the increased frequency of renal transplantation, renovascular hypertension and vascular reconstruction for congenital and acquired lesions (Ali-El-Dein et al., 2003; Makiyama et al., 2003; Khamanarong et al., 2004). Recent advances and refinements in urologic surgery as well as radiological interventional procedures have revived interest in renal arterial anatomy because a thorough understanding of such anatomy is essential for the safe and efficient performance of these procedures as well as aids in surgical planning to avoid potential complication (Smith et al., 1998). Renal transplantation is the permanent and safe treatment for patients with chronic renal failure (Lopes et al., 1998). However, the presence of multiple renal arteries increases the complexity of the 
transplant procedure and can be challenging for the transplant surgeon because each renal artery is a terminal vessel and its injury may produce segmental ischemia with subsequent hypertension (Benedetti et al., 1995; Troppmann et al., 2001). An important component of the evaluation of potential living-related kidney donors is the accurate determination of rena! arterial anatomy (Gourlay et al., 1995). Traditionally, conventional or digital-subtraction angiography has been used to outline the number, location and length of the renal arteries (Flechner et al., 1985). Recent studies have shown that minimally invasive procedures can be used to achieve a degree of accuracy ranging between $90-97 \%$, in case of using three dimensional magnetic resonance angiography (MRA), and up to $100 \%$, in case of using Three-dimensional computed tomographic (CT) angiography, in depiction of accessory renal arteries (Smith et al., 1998; Volk et al., 2000; Alvarez-Castells et al., 2001; Mittal et al., 2001; Volk et al., 2001).

The aim of this work is to determine the incidence of multiple renal arteries and to summarize some of their anatomical characteristics as well as to detect other coexisting renal variations, which could be equally important for surgeons and radiologist, using formalin-preserved human cadavers and angiographies of potential living-kidney donors.

\section{MATERIALS AND METHODS}

This study was performed on 54 human formalin-preserved cadavers (15 females and 39 males) and angiographies of 336 potential living-kidney donors (56 females and 280 males) with a total of 780 individual kidneys ( 142 female and 638 male).

\section{Dissection of human cadavers}

A midline abdominal incision was performed, the abdominal viscera was retracted and the peritoneum covering the posterior abdominal wall was dissected to expose the kidneys, renal vessels, ureter, inferior vena cava and abdominal aorta and its branches. The renal artery and any accessory one were dissected and demonstrated with evaluation of the following morphological parameters: the origin of these arteries, their caliber, course, direction, relation to the IVC and renal vein (or veins) as well as the level and the manner of their termination as they approaching the kidney. The origin of the inferior suprarenal artery and the presence of other renal variations coexisting with the double renal arteries on the same or opposite side were also depicted.

\section{Angiographic study}

A retrospective study of renal angiographies of 336 potential livingkidney donors attending King Fahd Transplantation Unit- Faculty of Medicine-Cairo University, during the period from August 2000 to April 
2004 , was done. The subjects were exposed to one or more of the following angiographic techniques:

1. Conventional Digital subtraction angiography (DSA): it was performed via a 5.0-French pigtail catheter placed ir the upper abdominal aorta using a standard Seldinger's technique. Digital subtraction filming was used and an oblique and/or selective imaging was performed at the discretion of the angiographer.

2. Three dimensional magnetic resonance angiography (3D MRA): MRA was performed using a three dimensional phase contrast technique with flow encoding in all three directions, 20 flip angle, velocity encoding $40 \mathrm{~cm} / \mathrm{sec}$, matrix size $192 \times 256,80 \%$ rectangular field of view, partition thickness $1.5 \mathrm{~mm}$, flow compensation, and one sequence average. Images were reconstructed using the maximum intensity pixel.

3. Three-dimensional multislice computed tomographic angiography (3D CTA): the usual scan length at the arterial phase imaging was approximately $25 \mathrm{~cm}$ to detect the main and the potential accessory renal arteries. With the use of four-section multi-detector row scanner and $4 \times 1$ $\mathrm{mm}$ collimation, rotation time of $0.5 \mathrm{sec}$., a table increment of $6 \mathrm{~mm} /$ rotation and table speed of $12 \mathrm{~mm} / \mathrm{sec}$, this volume was imaged in approximately 21 seconds.

All images were reviewed for the number of renal arteries on each side with evaluation of the above-mentioned parameters.

The following nomenclature was utilized to categorize the renal arteries: hilar artery (HA), an aortic branch that penetrate the kidney in the hilar region; upper polar (UPA), an aortic branch that penetrated the kidney at its superior pole; and lower polar artery (LPA), an aortic branch that penetrated the kidney at its inferior pole. The variations of the renal artery and their incidence and the morphological parameters of the multiple renal arteries were presented in Tables I and II, respectively.

\section{RESULTS}

\section{l-Single renal artery (Table I)}

A single renal artery was detected in $568 / 780$ cases $(72.8 \%)$. According to the manner of its termination on approaching the kidney, this artery was categorized into:

*An artery giving terminal branches close to or after penetrating the hilum of the kidney (Type I): it was demonstrated in $465 / 780$ cases (60 cadaver specimens and 405 kidneys of living renal donors). This type of 
renal artery was associated with normal anatomy of renal pedicle (Fig. 1-a) and gave rise to one or two inferior suprarenal arteries (Fig.1-b). However, an epsilateral coexisting vascular variations could be encountered in cases with contralateral renal arterial variations.

* An artery branched early, $3 \mathrm{~cm}$ or more, before reaching the kidney (Type II): it was detected in $103 / 780$ cases (16 cadaver specimens and 87 kidneys of living renal donors). The early branches of the main renal artery ended either in the hilum (Fig. 2) or in the upper pole (Figs. 3-a,b). Crossing of these branches to the main artery was demonstrated in 7 cases (Figs, 4-a,b) and coexisted other epsilateral uro-vascular variations were encountered.

\section{II- Multiple renal arteries (Tables I \& II)}

Multiple renal arteries originated from aorta were found in 212/ 780 cases $(27.2 \%), 32$ cadaver specimens and 180 kidneys of potential living renal donors, and the incidence was higher in males than in females, $186 / 638$ male specimens $(29.2 \%)$ and $26 / 142$ female specimens $(18.3 \%)$. There was a left predominance of the multiple renal arteries, where the left ones were located in $127 / 212$ cases $(59.9 \%)$. Bilateral multiple renal arteries were demonstrated in 28/212 cases (13.2\%) (Figs.5-a\&b). The multiple renal arteries were divided according to their numbers into:

\section{A- Double renal arteries}

They were found in 198/780 samples, 32 cadaver specimens and 166 kidneys of living renal donors with a left predominance (117/198 cases). In $52 / 198$ cases, the double arteries had a common aortic origin (Figs.6,7) while in 146/198 cases, they had separate origin from aorta; both originated from lateral side (Figs.8,9) or one from lateral side and the other one arose from anterolateral (Fig. 10-a) or posterolateral (Fig.11) aspect of aorta. The distance between the aortic origins of these double arteries was highly variable ranging between $1-2 \mathrm{~mm}$ and $4-6 \mathrm{~cm}$.

The caliber of the double renal arteries was similar in 106 specimens. In 86 cases of them, the two arteries end in the renal hilum (Figs.5-a,b,6,9) while in the other 20 cases, one artery ended in the renal hilum (HA) and the other one ended in the upper pole of the kidney (Figs. 12-a,b, 13). The double renal arteries, of the remaining 92 cases, had different calibers where in 61 cases, both arteries ended in the hilum (Fig. 7), and in 31 cases, the artery of the larger caliber terminate in the hilum (main artery) and that of smaller caliber entered the kidney through either the upper, 10 cases, (Fig.14) or the lower pole, 21 cases, (Fig.5-b). 
The course of the double renal arteries was variable. In 116/198 specimens, the two arteries was aimost parallel to each other from the aorta up to the kidney with possible orientations being oblique or horizontal (Figs. 9, 15-a,b). In 82/198 specimens, the two renal arteries showed different courses; in 40 cases, their courses were convergent (Fig.16), in 30 cases, they were divergent (Fig. 7) and in 12 cases, the two arteries crossed each other (Figs.11,17). The two arteries had either straight or sinuous course (Fig 16) or one was straight and the other one was sinuous (Figs.10-a,b).

As regard their renal approach, in $147 / 198$ cases, the two arteries were HAs. In the other cases $(51 / 198)$, one artery was a HA and the other one was either an UPA, 30 cases, or a LPA, 21 cases. The polar arteries entered the kidney, as a penetrating branch, most often, on the medial border (Fig. 13) and in 5 cases only, on the anteromedial aspect (Fig.5-b) of the renal pole.

In most cases $(116 / 198)$, the terminal divisions of the double renal arteries were inside the kidney, while in 53/198 cases, one or the two renal arteries gave branches close to the hilum, when they were hilar (Fig.9), or close to the renal pole, when they were polar (Fig.14). In 29cases of double renal arteries of different caliber, the larger artery (main renal artery) divided early into two branches; either both entered the hilum (21 cases) (Fig.5-b) or one entered the hilum and the other one enter the upper pole of the kidney ( 8 cases) (Fig. 15-a,b).

\section{B- Triple renal arteries}

Triple renal arteries were recorded in $13 / 780$ cases $(1.67 \%)$, all from potential living renal donor cases, with left predominance ( 9 cases). They had separate origin from aorta and different calibers; only one case showed similar calibers of the three renal arteries (Fig.18). In all cases, the arteries showed either straight or curved course. In 4 cases, the arteries passed parallel to each other (Fig.18), in 2 cases, they crossed one another (Fig. 19 ) and in 7 cases, they were convergent (Figs. 20-a,b,c). On approaching the kidney, the three arteries either ended in the hilum ( 9 cases) (fig. 19) or two ended in the hilum and the third one terminated in the upper pole ( 4 cases) (Fig.18). In 10 cases, the arteries branched inside the kidney and in 3 cases, one or more of these arteries branched close to the kidney (Fig. 20 c). No early branched arteries were detected.

\section{C-Quadruple renal arteries}

Only one case $(1 / 780,0.13 \%)$ was recorded in a subject having four renal arteries of variable calibers on the left side with three renal arteries on the right side (Figs.20-a, b, d). The quadruple arteries had separate aortic origin, different calibers and converge towards the kidney. Two arteries 
were hilar while the other two arteries were upper and lower polar arteries (fig. 20-d). No prehilar branches were detected.

\section{Associate anatomical variations}

Other urovascular anatomical abnormalities coexisted with the renal artery variations, either on ipsi- or contralateral side, were recorded, only in the dissected specimens (108 cases) as those of angiographies of potential living kidney donors were not reliable.

\section{A-Variations of the origin of the inferior suprarenal artery}

${ }^{*}$ Epsi - or contralateral aortic origin of the inferior supra renal artery in common stem with the middle suprarenal one was recorded in 3 cases. In one case, this was associated with posterior relation of the renal vein to the renal artery, at the renal pedicle, with anterior crossing of the suprarenal vein to the renal artery (Figs. 21).

*One or two inferior suprarenal branches originated from the upper one of the double renal arteries (Figs.9,10-a,b) was recorded in 30 cases.

B- Anatomical variations of the renal vein

They were recorded in epsi- or contralateral side of some cases of double renal arteries, or with those of type II single renal arteries and showed higher incidence on the left side.

*A left renal vein was demonstrated crossing the aorta either obliquely and anteriorly hooking around the renal artery, in 3 cases (Fig.22), horizontally and anteriorly running below and parallel to the renal artery, in 3 cases (Fig.21), or horizontally and posteriorly, in 4 cases, (Fig.8). In all these venous variations, the renal vein entered the hilum posterior to the renal artery (or arteries) or its branches.

${ }^{*} \mathrm{~A}$ right renal vein entered the hilum deep to right double renal artery or the prerenal branched one was recorded in 3 dissected specimens (Figs. 4-a,b,9).

*Double left renal veins, one anterior to the other with the renal artery and the renal pelvis between the two veins, was recorded in 2 cases. The two veins united into one stem before crossing superficial to the aorta (Fig.23) to end in the inferior vena cava.

*A left renal vein, crossed both superficially and deeply by double renal arteries and dividing into two parts surrounding the aorta (renal vein collar) before ending separately into the inferior vena cava, was recorded in 2 cases (Figs. 10-a,b). 
*A renal vein situated between the anterior and posterior branches of early divided renal artery was demonstrated in 3 cases on the left side and in 2 cases on the right side (Fig.,24).

\section{C- Other coexisted anatomical variations}

*An early-branched right renal artery crossing anterior to the inferior vena cava was demonstrated in 3 specimens. (Figs. 4-a,b).

*Branches of early divided renal artery passing anterior as well posterior to the pelvis of the ureter, was recorded in 6 specimens (Figs. 24,25)

${ }^{*}$ Coexistence of polycystic kidney was seen in 4 cases (fig. 4-a,b).

Table I: Renal artery variations and their incidence

\begin{tabular}{|c|r|r|r|r|r|r|l|}
\hline \multirow{2}{*}{ Type } & \multicolumn{3}{|c|}{ Single renal artery } & \multicolumn{4}{c|}{ Multiple renal artery } \\
\cline { 2 - 7 } & Type I & Type II & total & Double & Triple & Quadruple & Total \\
\hline No. of cases & 465 & 103 & $568 / 780$ & 198 & 13 & 1 & $212 / 780$ \\
\hline Percentage & 59.6 & 13.2 & 72.8 & 25.4 & 1.67 & 0.13 & 27.2 \\
\hline $\begin{array}{c}\text { Predominant } \\
\text { side }\end{array}$ & \multicolumn{3}{|c|}{ Right side } & \multicolumn{4}{|c|}{ Left side } \\
\hline
\end{tabular}


Table II: Morphological parameters of the multiple renal arteries

\begin{tabular}{|c|c|c|c|c|}
\hline Type of renal artery & $\begin{array}{c}\text { Double } \\
\text { No. } / 198 \\
\text { cases }\end{array}$ & $\begin{array}{l}\text { Triple } \\
\text { No./13 } \\
\text { cases }\end{array}$ & $\begin{array}{l}\text { Quadruple } \\
\text { One case }\end{array}$ & $\begin{array}{c}\text { Total } \\
\text { No./212 }\end{array}$ \\
\hline $\begin{array}{l}\text { Aortic origin: } \\
{ }^{*} \text { Common aortic origin } \\
{ }^{*} \text { Separate aortic origin }\end{array}$ & $\begin{array}{r}52 \\
146\end{array}$ & $\begin{array}{l}-- \\
13\end{array}$ & $\begin{array}{l}-- \\
1\end{array}$ & $\begin{array}{c}52 \\
160\end{array}$ \\
\hline $\begin{array}{l}\text { Caliber: } \\
{ }^{*} \text { Similar calibers } \\
\text { *Different calibers }\end{array}$ & $\begin{array}{l}106 \\
92\end{array}$ & 13 & $\begin{array}{l}-- \\
1\end{array}$ & $\begin{array}{l}106 \\
106\end{array}$ \\
\hline $\begin{array}{l}\text { Course: } \\
\text { *Parallel to each other } \\
{ }^{*} \text { Convergent towards hilum } \\
\text { *Divergent towards hilum } \\
\text { "Crossing each other }\end{array}$ & $\begin{array}{l}116 \\
40 \\
30 \\
12\end{array}$ & $\begin{array}{l}4 \\
7 \\
- \\
2\end{array}$ & $\begin{array}{l}-- \\
1 \\
-- \\
--\end{array}$ & $\begin{array}{l}120 \\
48 \\
30 \\
14\end{array}$ \\
\hline $\begin{array}{l}\text { Renal approach: } \\
\text { * All hilar } \\
\text { * Hilar + upper polar } \\
{ }^{*} \text { Hilar + lower polar } \\
\text { *Hilar + Upper \& lower polar }\end{array}$ & $\begin{array}{l}147 \\
30 \\
21 \\
-\end{array}$ & $\begin{array}{l}9 \\
4 \\
- \\
--\end{array}$ & $\begin{array}{l}- \\
-- \\
-- \\
1\end{array}$ & $\begin{array}{c}156 \\
34 \\
21 \\
1\end{array}$ \\
\hline $\begin{array}{l}\text { Manner of branching: } \\
{ }^{*} \text { branched inside the kidney } \\
{ }^{*} \text { Branched close to kidney } \\
{ }^{*} \text { Early branched before kidney }\end{array}$ & $\begin{array}{l}116 \\
53 \\
29\end{array}$ & $\begin{array}{l}10 \\
3 \\
--\end{array}$ & $\begin{array}{c}1 \\
-- \\
--\end{array}$ & $\begin{array}{r}127 \\
56 \\
29\end{array}$ \\
\hline
\end{tabular}


Table III: Percentage of multiple renal arteries and geographical zone of the cases studied in the present work and by other workers

\begin{tabular}{|l|c|l|c|}
\hline \multicolumn{1}{|c|}{ Authors } & No. of cases & MRA \% & Geographical zone \\
\hline Sampaio and passos (1992) & 266 & 38.2 & Brazil \\
\hline Chugh et al. (1993) & 170 & 21.2 & India \\
\hline Shokeir et al. (1994) & 1000 & 28.1 & Egypl \\
\hline Goscicka et al. (1996) & 280 & 21.3 & Geman \\
\hline Halpern et al. (1999) & 130 & 25 & USA \\
\hline Satyapal et al. (2001) & 472 & 27.7 & South Africa \\
\hline Makiyama ct al. (2003) & 393 & 24.4 & Japan \\
\hline Khamanarong et al. (2004) & 534 & 17.4 & Thailand \\
\hline Bordei et al. (2004) & 272 & 20 & Romania \\
\hline Present work & 780 & 27.2 & Egypl \\
\hline
\end{tabular}

MRA\%= the percentage of multiple renal arteries
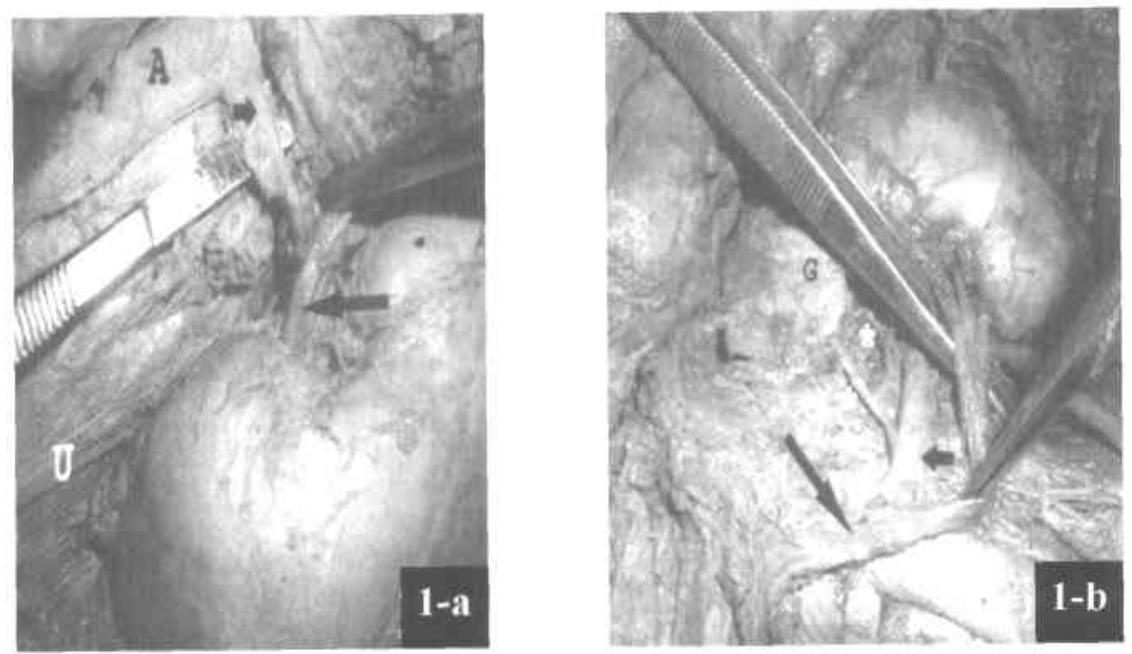

Figs. $(1-a, b)$ : Photographs of dissected abdomens of formalin preserved cadavers showing:

(a): Left kidney with single renal artery (short arrow) and normal renal pedicle. The renal vein (long arrow) is displaced upwards to demonstrate the aortic origin of the renal artery and its course. Note the aorta (A) and the ureter $(\mathrm{U})$.

(b): Two inferior suprarenal branches $\left(^{*}\right)$ originate separately from the single renal artery (short arrow) to supply the suprarenal gland (G). Note the renal vein (long arrow) displaced downward. 


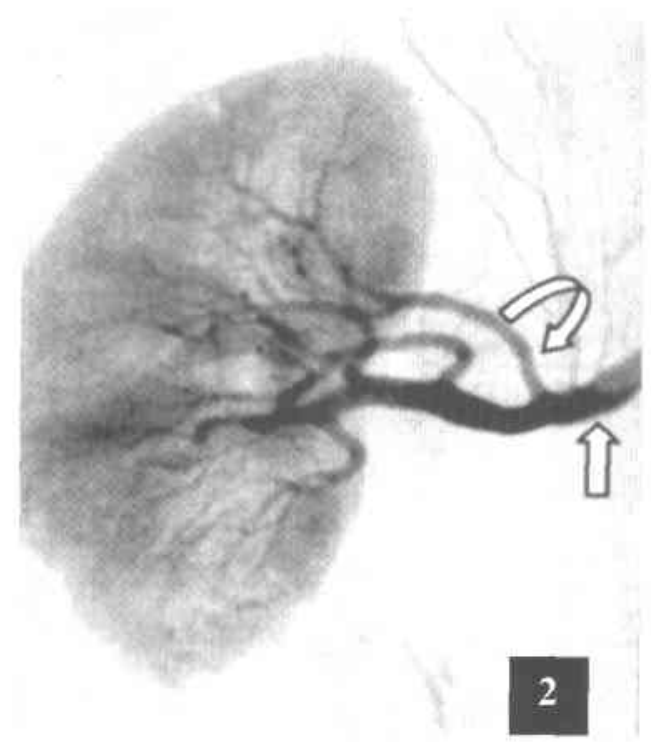

Fig. (2): Conventional DSA of the right kidney showing early division (curved arrow) of the right main renal artery (straight arrow). Note that all branches end in the renal hilum.
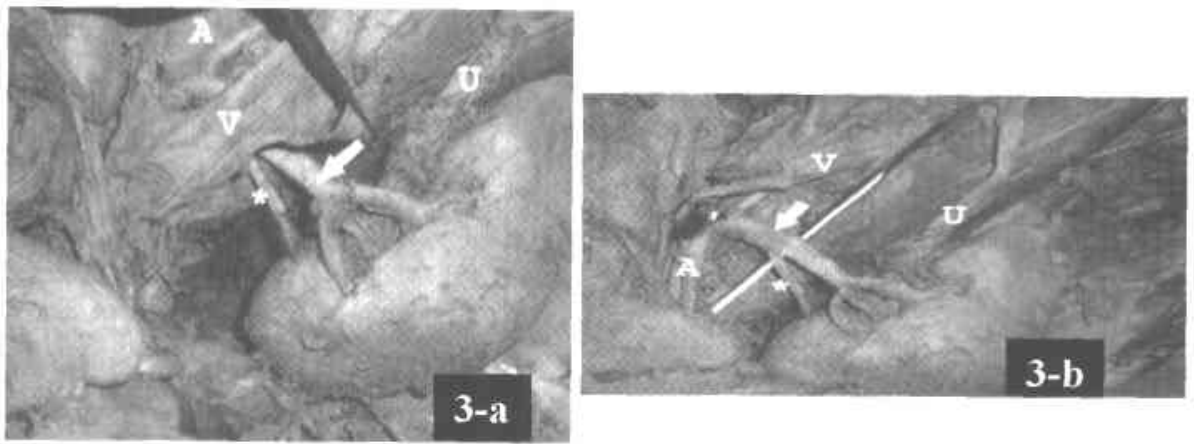

Figs. (3-a,b): Photographs of a dissected abdomen of a formalin preserved cadaver showing right renal artery (arrow) giving an early branch $\left({ }^{*}\right)$ that ends in the upper pole of the kidney. Note the ureter $(U)$, the aorta $(A)$, and the left displacement of the inferior vena cava ( $V$ in Fig.(3-b). 

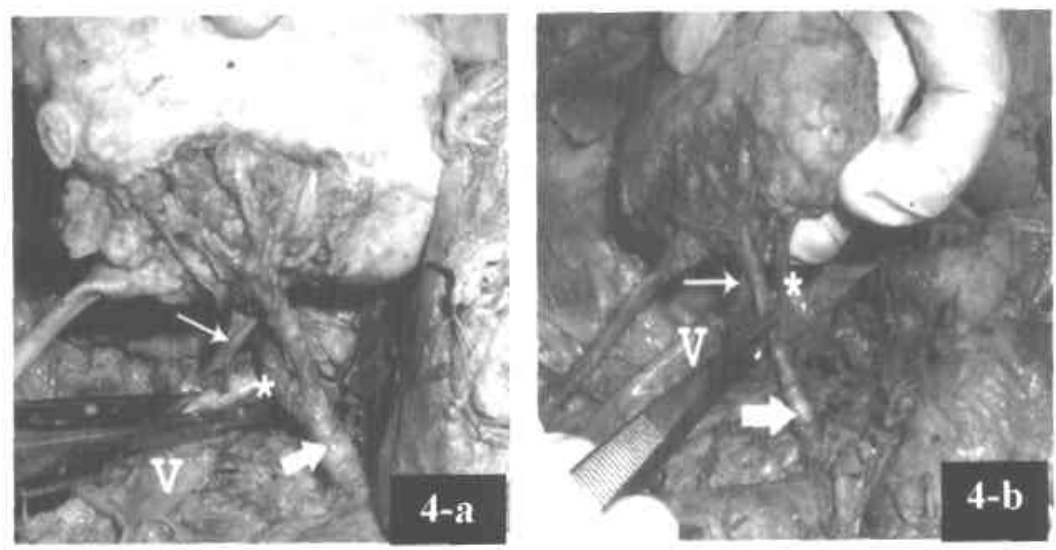

Figs. (4-a, b): Photographs of a dissected abdomen of a formalin preserved cadaver showing right polycystic kidney with an early branch arising $\left(^{*}\right)$ from the lower aspect of the main renal artery (thick arrow). Note that the kidney and the main renal artery are twisted forward (Fig. 4-b), to show the posterior crossing of the early branch to the main renal artery to reach the upper pole. Superficial crossing of the renal artery to the inferior vena cava $(V)$ and the deep position of renal vein (thin arrow) to the main renal artery at the hilum can be seen.
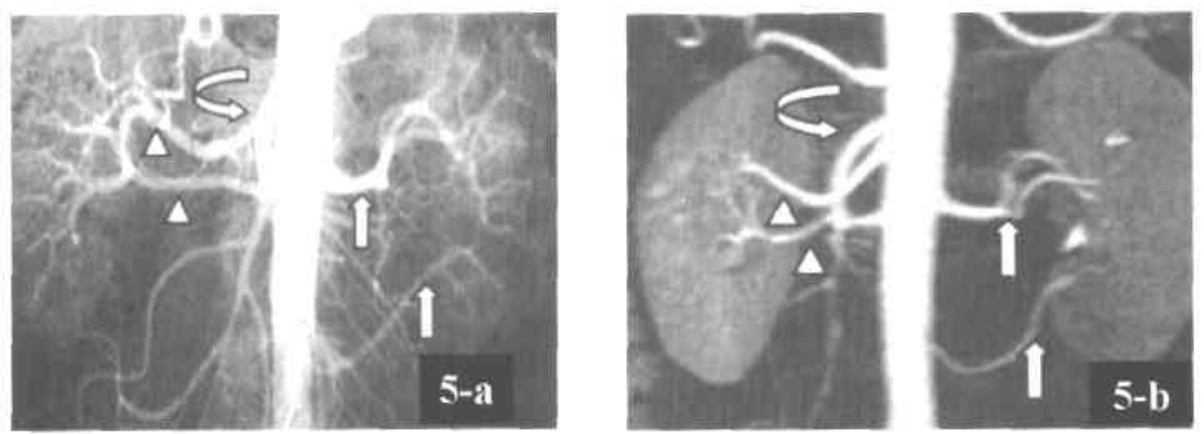

Fig. (5-a,b): Conventional DSA and MRA, respectively, of both kidneys of a case of bilateral double renal arteries. The right arteries (arrowheads) are of equal caliber and both are hilar. The left double arteries (arrows) are of different caliber where the larger one divides early into two branches, both entering the hilum while the smaller one is seen, in Fig. (5-b), ending in the anteromedial aspect of lower pole. Note the superior mesenteric artery (curved arrow). 


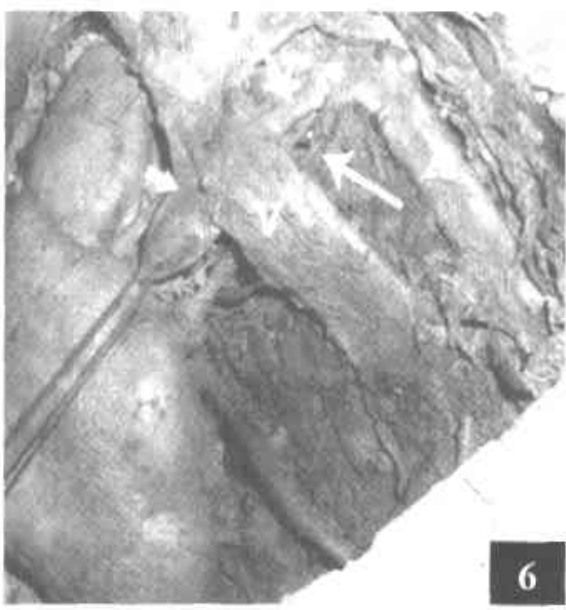

Fig. (6): A photograph of a dissected abdomen of formalin preserved cadaver showing right double renal arteries (long arrows) of common aortic origin and similar caliber, both ending in the hilum. Note the renal vein (short arrow), the inferior vena cava $(V)$ and the aorta (A).

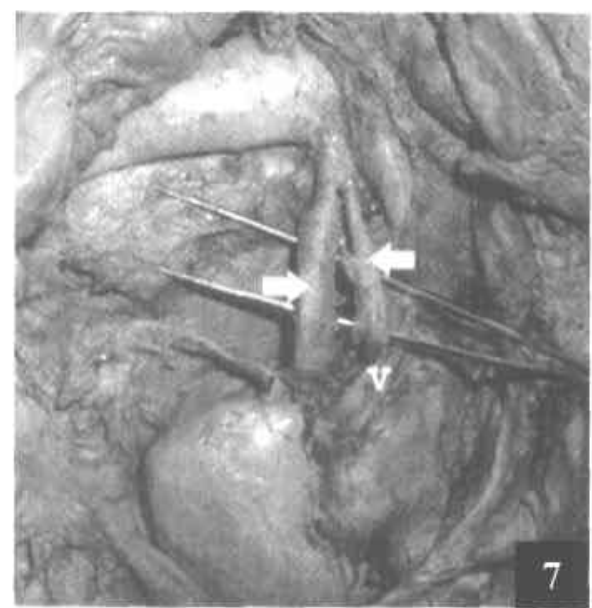

Fig. (7): A photograph of a dissected abdomen of formalin preserved cadaver showing left double renal arteries (arrows) of common aortic origin and different caliber. They have divergent course and both end in the hilum. Note the aorta $(A)$ and the reflected renal vein $(v)$.

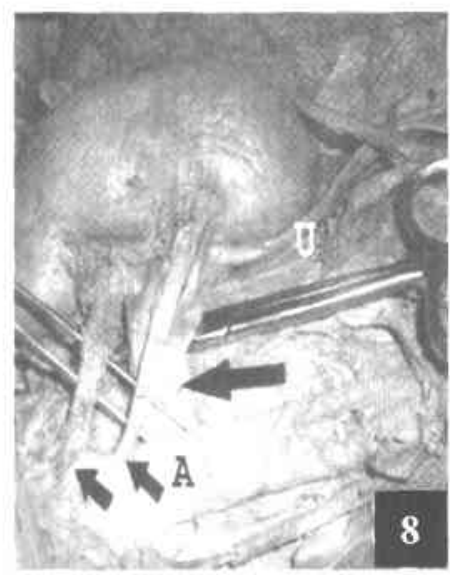

Fig. (8): A photograph of a dissected abdomen of a formalin preserved cadaver showing left double renal arteries (short arrows) originated separately from the lateral aspect of the aorta $(A)$ and both ending in the hilum. Note the ureter $(U)$ and the horizontal course of the renal vein (long arrow) crossing the aorta posteriorly to reach the renal hilum deep to the arteries. 

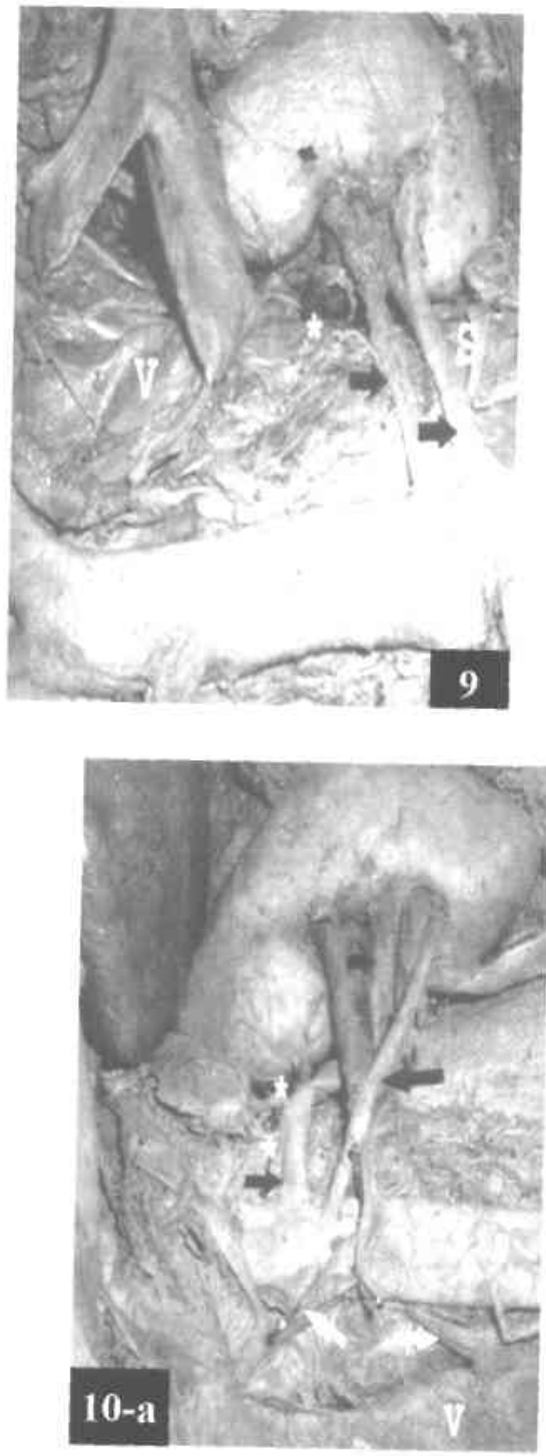

Fig. (9): A photograph of a dissected abdomen of a formalin preserved cadaver. The IVC (V) is cut and reflected downward to demonstrate right double renal arteries (arrows) of similar caliber and originating separately from lateral aspect of aorta. The arteries run obliquely and parallel to each other and branch on approaching the hilum. An inferior suprarenal artery (S) arising from the upper renal artery can be seen. Note the cut renal vein (*) located posterior to the arteries at the hilum.

Figs. $(10-a, b)$ : Photographs of a dissected abdomen of a formalinpreserved cadaver showing left double renal arteries, one is straight (long arrow) and one is sinuous (short arrow). The upper artery gives two inferior suprarenal branches $\left(^{*}\right)$. The renal vein is crossed both superficially and deeply by the double renal arteries, then divides into two parts (crossed arrows) surrounding the aorta before ending separately in the inferior vena cava (V). Note the superficial part of the renal vein is displaced downwards, in Fig. (10-a), to demonstrate the anterolateral aortic origin of the lower renal artery. 


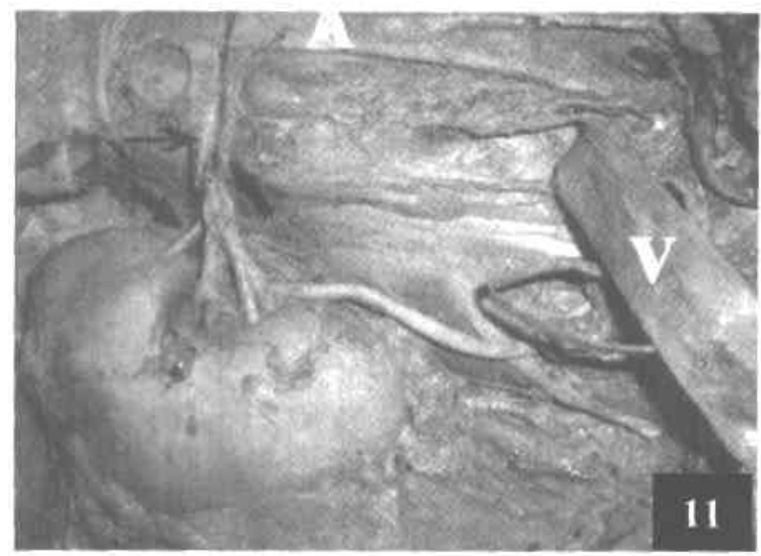

Fig. (11): A photograph of a dissected abdomen of a formalin preserved cadaver showing right double renal arteries originated from the lateral (thin arrow) and posterolateral (thick arrows) aspects of the aorta (A) and crossing each other. Note the reflected inferior vena cava $(V)$.
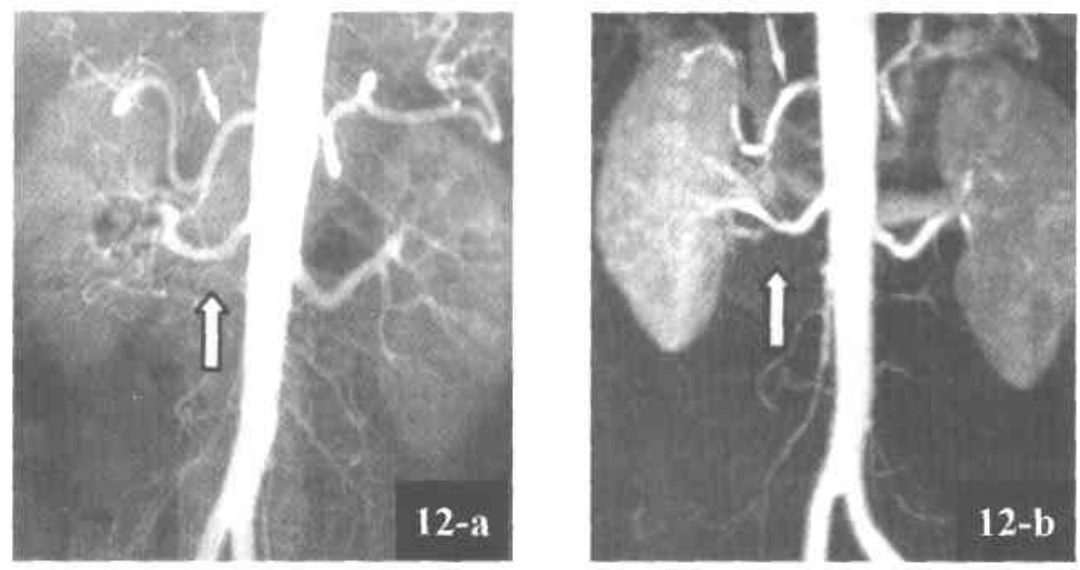

Fig. (12-a,b): Conventional DSA and MRA, respectively, of both kidneys of a case showing right double renal arteries of similar caliber; one is hilar (thick arrow) and one is upper polar (thin arrow). 


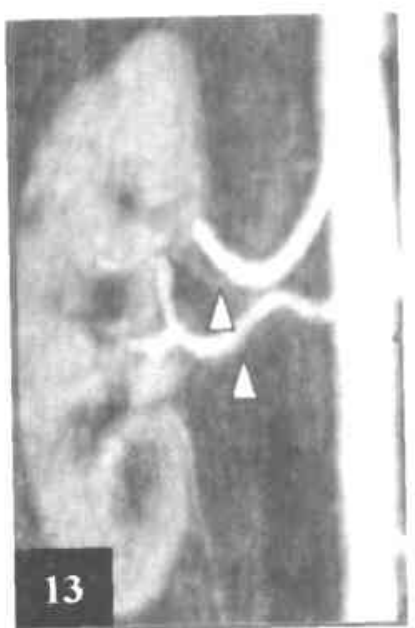

Fig. (13): MRA of the right kidney showing right double renal arteries of similar caliber (arrowheads); one ends in the hilum and one ends in the medial border of the upper pole.

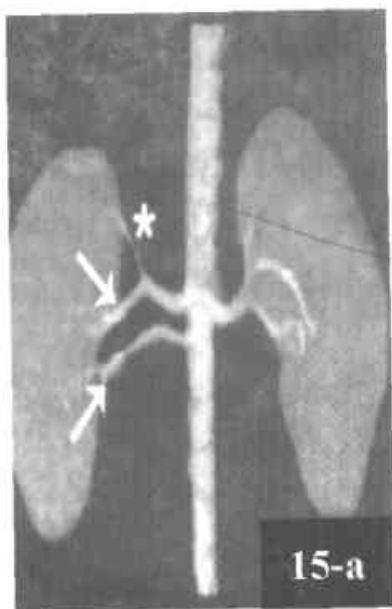

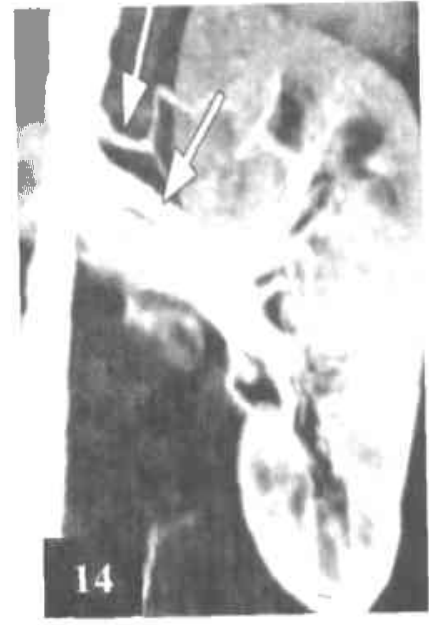

Fig. (14): MRA of the left kidney showing left double renal arteries of different caliber (arrows); the larger is hilar and the smaller is upper polar branching close to the renal pole.

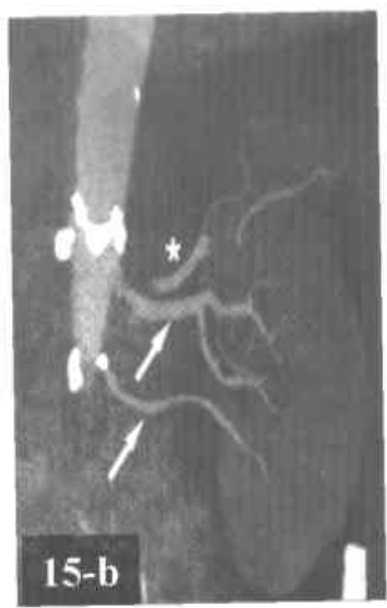

Fig. $(15-a, b): 3 D$ CT angiographies of kidneys of two different cases showing:

(a): Right double renal arteries having an oblique parallel course and different caliber (arrows). The two arteries end in the hilum with the larger one giving an early upper polar branch $\left(^{*}\right)$.

(b): Left double renal arteries having a horizontal parallel course and different caliber (arrows). Note the larger artery giving an early upper polar branch (*) before entering the renal hilum. 


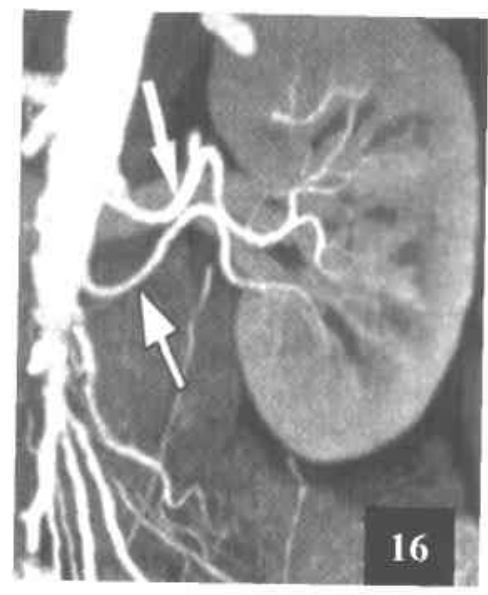

Fig. (16): MRA of the left kidney showing left double renal arteries (arrows) having a sinuous course and converging towards the hilum of the kidney.

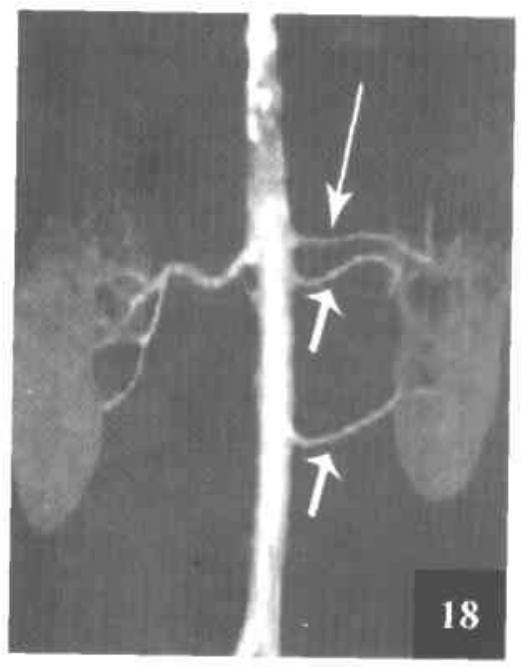

Fig. (18): 3D CT angiography of both kidneys showing left triple renal arteries of similar calibers and parallel course. Two of them end in the hilum (short arrows) and the third one ends in the upper pole (long arrow).

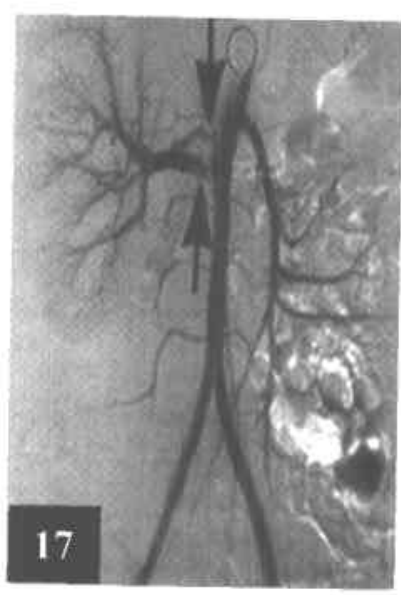

Fig. (17): Conventional DSA of the aorta showing right double renal arteries (arrows) crossing each other.

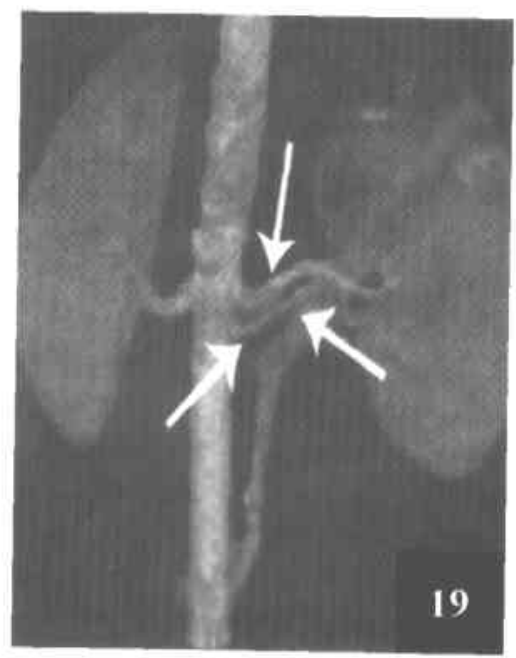

Fig. (19): 3D CT angiography of both kidneys showing left triple renal arteries (arrows) crossing each other and all ending in the hilum. 

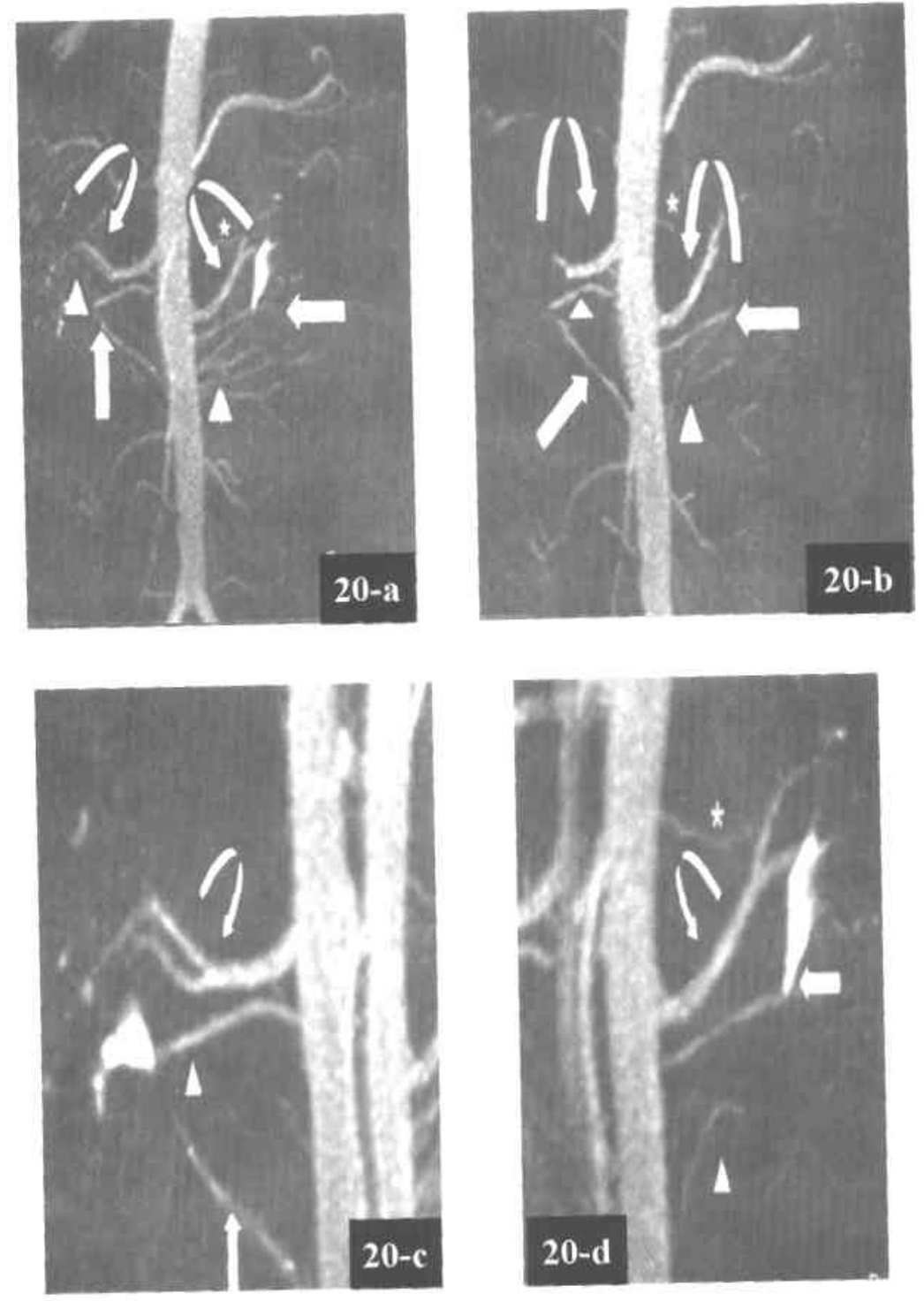

Fig. (20-a,b,c,d): MRA images of the aorta of a case of bilateral multiple renal arteries showing:

$(20-a, b, c)$ : Right triple renal arteries (curved arrow, arrowhead and straight arrow) converge towards the kidney. Note the upper larger one (Fig. 20-c) branches close to the kidney.

$(20-a, b, d)$ : Left quadruple renal arteries of different caliber and separate aortic origin. They converge towards the kidney. Note that two arteries are hilar (curved and straight arrows) while the other two arteries are upper $\left(^{*}\right)$ and lower (arrowhead) polar. 


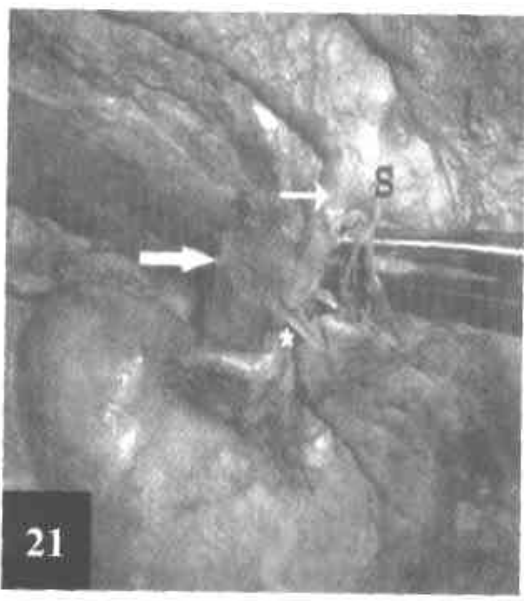

Fig. (21): Photographs of a dissected abdomen of a formalin preserved cadaver showing aortic origin of the left inferior supra renal artery in common stem with the middle suprarenal ( $(S)$. The left renal vein (thick arrow) passes below and parallel to the renal artery (thin arrow) to enter the renal pedicle deep to the artery. Note the anterior crossing of the suprarenal vein $\left({ }^{*}\right)$ to the renal artery.

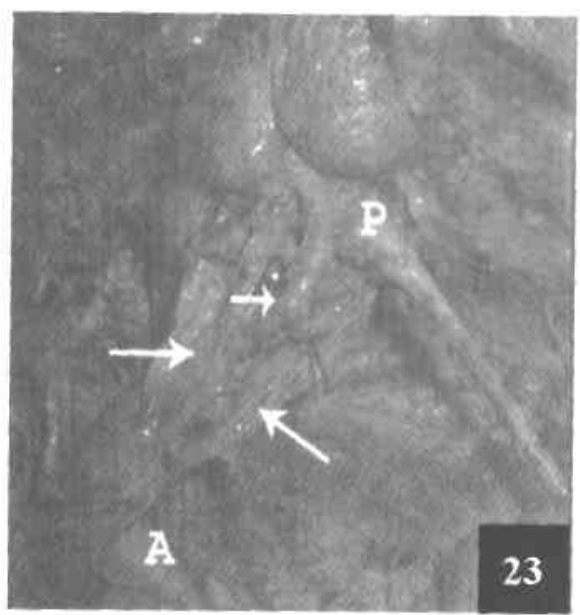

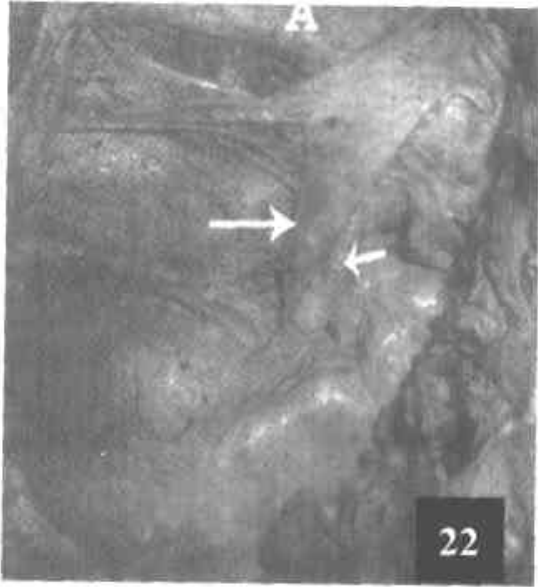

Fig. (22): A photograph of a dissected abdomen of a formalin preserved cadaver showing the left renal vein crossing (long arrow) the aorta (A) obliquely and anteriorly hooking around the renal artery (short arrow) to enter the renal hilum deep to the artery.

Fig. (23): A photograph of a dissected abdomen of a formalin preserved cadaver showing left double renal vein, one anterior to the other (long arrows) with the renal artery (short arrow) and the renal pelvis $(P)$ between the two veins. Note the union of the two veins into one stem before crossing superficial to the aorta (A). 


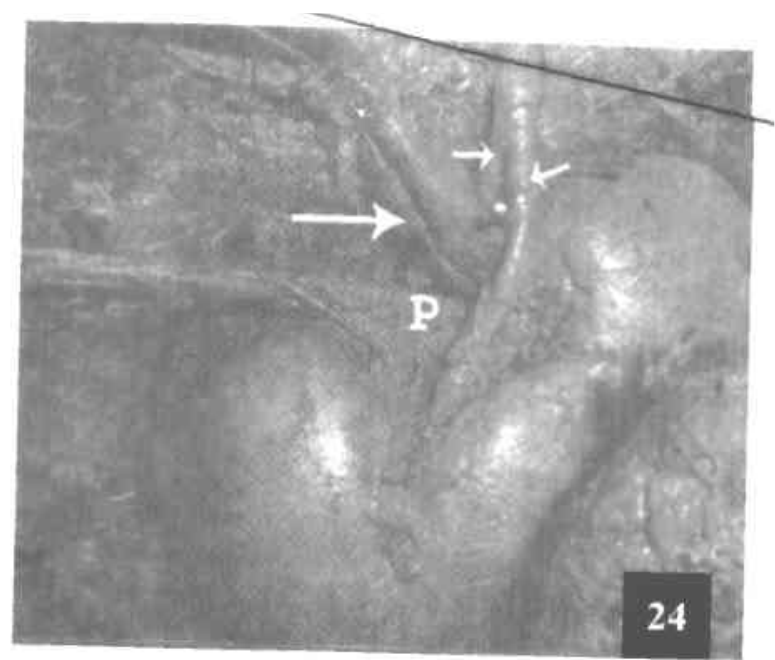

Fig. (24): A photograph of a dissected abdomen of formalin preserved cadaver showing early division of the left renal artery into two branches (short arrows), one anterior to the other, enclosing the renal vein (long arrow) and the pelvis of the ureter $(P)$ between them.

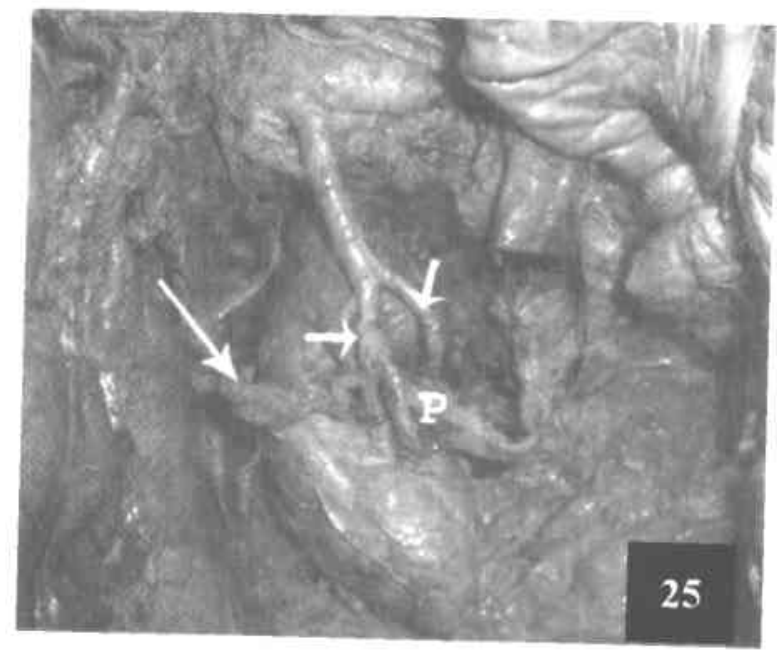

Fig. (25): A photograph of a dissected abdomen of formalin preserved cadaver showing branches (short arrows) of early divided right renal artery passing anterior as well as posterior to the pelvis of the ureter $(P)$. Note the cut renal vein (long arrow). 


\section{DISCUSSION}

Accessory renal arteries with an aortic origin are a frequent vascular variation and represent the persistence of the embryonic vessels, the fetal branches of the mesonephros, during the renal ascent (Williams et al., 1995; Langman and Sadler, 1996). The present work showed that the incidence of multiple renal arteries was $27.2 \%$ (212/780 cases). This finding is in perfect correspondence with that of Shokeir et al. (1994) and Satyapal et al. (2001) who worked on Egyptian and South African cases and reported an incidence of $28.1 \%$ and $27.7 \%$, respectively, for the multiple renal arteries. However, the value in the literature varies from $17 \%$ to $38 \%$ (Table III). The variation in the incidence of multiple renal arteries among those authors who worked on cases of different geographical zones (table III) may be explained by particularities that are racial characters (Bordei et al., 2004). Such explanation is strongly supported by the study of Satyapal et al. (2001) which demonstrated the incidence of multiple renal arteries, according to the ethnic origin, to be $36.5 \%$ in Africans, $35.3 \%$ in Caucasians, $19 \%$ in Indians, and $18.5 \%$ in half-caste population with an average incidence of $27.7 \%$. Furthermore, Bordei and Antohe (2002) suggested that in the same geographical area, different environmental factors could be involved, mostly during organogenesis, offering a possible explanation for the differences over time in a population of the same geographical zone. Satyapal et al. (2001) also identified significant difference between sexes where the incidence was higher in males (28\%) than in females (16.44) and this finding is in full similarity to that deduced from the present work. Likewise, Makiyama et al. (2003) stated that their findings implied that men tend to have multiple renal arteries more than women (more prevalent in men than in women). However, Chugh et al. (1993) found higher incidence in female than in males. On the other hand, Pollak and Mozes (1986) reported that gender did not significantly influence the number of renal arteries. The difference in literature regarding the frequency of double renal arteries may be also attributed to the different techniques used to reveal them ( Halpern et al., 1999; Satyapal et al., 2001; Bordei et al., 2004). Halpern et al. (1999) compared conventional angiography (CA), computed tomographic (CT) angiography, and magnetic resonance (MR) angiography for the evaluation of accessory renal arteries in the same subjects. They found that CA revealed incidence of $24 \%$ of accessory renal arteries and CT angiography revealed incidence of $32 \%$ while MRA showed incidence of $20 \%$. Moreover, Benedetti et al. (1995) attributed the lower incidence of multiple renal arteries recorded in their series $(20 \%)$ than most of those reported in the literature to the large number of living related and living unrelated donors used in their program.

The present results are quite similar to those of Satyapal et al. (2001) and Bordei et al. (2004) who described the existence of double renal arteries mostly on the left side, but in contradiction with the data of 
Goscicka et al. (1996), who worked on human fetuses of different ages and suggested a higher frequency on the right. As regard the appearance of bilateral multiple renal arteries, the present result demonstrated bilateral accessory renal arteries in $28 / 212$ cases $(13.2 \%)$. This finding is compatible with that reported by Chugh et al. (1993), Satyapal et al. (2001) and Bordei et al. (2004) who demonstrated it in nearly $11 \%$ of cases of multiple renal arteries. Lower incidence was reported by Shokeir et al. (1994) who found that $26 / 281$ cases $(9.25 \%)$ of the multiple renal arteries were presented bilaterally. On the other hand, higher incidence was demonstrated by Pollak and Mozes (1986) who reported bilateral multiple renal arteries in $15 \%$ of all cases.

In the current morphological study, the multiple renal arteries that terminate all in the renal hilum (hilar arteries) were reported in 156/212 cases and these hilar arteries were of equal caliber in $86 / 156$ cases $(55 \%)$. This value was higher than that reported by Bordei et al. (2004) who demonstrated hilar arteries of identical caliber in $35 \%$ of their cases. They found that these arteries supplied equal-sized renal territories so that they classified both of them as being main renal arteries. The present work showed that the incidence of multiple renal arteries of hilar and upper polar category, $34 / 212$ cases $(16 \%)$, was higher than those of hilar and lower polar one, $21 / 212$ cases $(9.9 \%)$. A similar finding was revealed by Sampaio and Passos (1992), Vilhova et al. (2001 and 2002), Makiyama et al. (2003) and Khamanarong et al. (2004). Although the number of multiple renal arteries reported by the above mentioned authors are nearly similar (93 102 cases), the incidences of the upper and lower polar arteries reported by them are quite variable ranging between $7.32 \%$ for the upper polar versus $3.56 \%$ for the lower polar arteries in the study of Khamanarong et al. (2004) and $30.7 \%$ for the upper polar versus $14.6 \%$ for the lower polar arteries in the study of Makiyama et al. (2003). On the contrary, Bordei et al. (2004) who worked on adult and fetal specimens demonstrated higher incidence of multiple renal arteries of hilar with lower polar $(30 \%)$ than those of hilar with upper polar arteries $(9 \%)$. In addition, Bordei et al. (2004) found that in 5 cases out of 19 double hilar arteries of equal caliber, one of the two arteries divided in a prehilar location into two branches one hilar and the other polar. However, the present work demonstrated such early branching by the larger artery (main renal artery) in cases of double arteries of different caliber.

The current work recorded triple renal arteries in $13 / 780$ cases (1.6\%) where in 9 cases, the three arteries were hilar and in 4 cases, two arteries were hilar and the third one was upper polar. These findings partially matches those represented by Khamanarong et al. (2004) who found triple renal arteries in $1 \%$ of their cases (5/534 cases) but they were either 2 hilar and one upper polar ( 2 cases) or 2 hilar and one lower polar ( 3 cases). On the other hand, higher incidence of triple renal arteries of $4.5 \%$, 
$3 \%$ and $4 \%$, was recorded by Satyapal et al. (2001), Vilhova et al. (2001) and Makiyama et al. (2003) respectively.

Cases of quadruple renal arteries are very seldom and were demonstrated in $1 / 780$ cases $(0.13 \%)$ of the present study. Apart from the study of Pollak and Mozes (1986), which revealed quadruple renal arteries in 1\% of their cases and up to our knowledge, no further studies in the literature recorded such renal arterial variation.

Bordei et al. (2004) demonstrated multiple variations in the course of double renal arteries such as retroureteral passage, right supplementary passing anterior to the inferior vena cava (IVC) and crossed course of double renal arteries. Similar observation was demonstrated in the present study, in case of double renal arteries or the early-branched ones, with different incidence of occurrence than that reported by previous authors. Associated arterial variations such as genital artery originating from the supplementary renal artery, ipsilateral double testicular arteries and unilateral origin of the inferior phrenic from the accessory renal artery with aberrant suprarenal arteries arising from the upper polar artery were also revealed in the previous works (Bakheit and Motabagani, 2004; Bordei et al., 2004). Coexisting renal vein anomalies or variations, such as posterior relation of the renal vein to the double renal arteries at the renal pedicle, double renal veins, left renal vein collar (around aorta) and retro-aortic left renal vein, were reported in the current as well as in the previous studies (Satyapal et al., 2001; Bordei et al., 2004; Khamanarong et al. 2004). The present work demonstrated the left predominance of the coexisting venous variations. This is confirmed by the findings of Bordei et al. (2004). However, Satyapal et al. (2001) recorded these variations on the left side only. In addition, Bordei et al. (2004) reported cases of double renal arteries with persistent fetal renal lobulation of the adult kidney; an observation similar to that revealed in the present work. Furthermore, bilateral or unilateral ureter duplication with unilateral multiple renal arteries was reported by Turgut et al., (2001) and Bordei et al. (2004), respectively.

Khamanarong et al. (2004) attributed the incidence of anomalous renal pedicles to embryological development of the kidneys where they failed to rotate medially when they ascent from the pelvis to the abdomen. The authors added that the awareness of such anomaly is crucial for surgeons performing pyelolithotomy.

The medical and surgical importance of the existence of multiple renal arteries is demonstrated in almost all the scientific papers. The presence of multiple donor renal arteries could be challenging for the transplant surgeon because each renal artery is a terminal vessel and its injury may produce segmental ischemia with subsequent hypertension (Evan et al., 1996). Consequently, Lechevallier et al. (1995) concluded that renal arterial anatomy is a selection criterion for the donor and recipient, which must 
be taken into account in renal transplantation. Sampaio and passos (1992) and Satyapal et al. (2001) added that the presence of double renal arteries increases the complexity of the process of renal transplantation itself as these arteries need reconstructive surgery. Other urovascular complications of multiple renal arteries include constriction of the upper portion of the ureter by the lower polar artery leading to hydronephrosis (Bush et al., 1989), injury of the lower polar artery (main nutrition of the ureter) during surgery leading to ureter necrosis (Desgrandchamps et al., 1998) and complications developed in suprarenal gland as a result of injury of the upper polar artery that may provide the inferior suprarenal branches (Sampaio and Passos, 1992). Moreover, renovascular hypertension resulted from an isolated accessory renal artery stenosis with patent main renal artery is one of serious sequences of multiplicity of this artery (Berland et al., 1990). Bude et al. (2003) emphasized that it is necessary to study accessory arteries when screening the renal arteries for renovascular hypertension, as the prevalence of hemodynamically significant stenosis, isolated to an accessory renal artery, was $1.5 \%$ in their study. In addition, Glodny et al. (2001) reported that $80 \%$ of patients suffering from essential hypertension were proved to have an aberrant renovascular anatomy. They explained that the longer and narrower accessory arteries, than the segmental arteries normally arising from the main renal artery, result in lower levels of blood pressure in the renal segments, thereby increasing rennin secretion.

On conclusion, multiplicity of renal artery is a common variant with expectation of coexistence of other urovascular anomalies. An awareness of the incidence of these variants is equally important for surgeons and radiologists and should be considered in preparation for urosurgical interventions. This necessitates preoperative renal angiography for the appropriate consideration of operative techniques.

\section{SUMMARY}

The aim of this work was to determine the incidence of multiple renal arteries and to summarize some of their anatomical characteristics, which could be equally important for surgeons and radiologists. The study was performed on 54 human formalin-preserved cadavers and renal angiographies of 336 potential living-kidney donors with 780 individual kidneys (142. female and 638 male). The formalin-preserved cadavers were dissected to expose the renal artery and any accessory one with evaluation of the following: the origin of these arteries, their caliber, the course and the manner of their termination as well as other coexisting urovascular variations on the same or opposite side. A retrospective study of renal angiographies of 336 potential living-kidney donors was done. The subjects were exposed to one or more of the following angiographic techniques: conventional digital subtraction, three-dimensional multislice computed tomography and threedimensional magnetic resonance. The renal arteries in all images were evaluated in the same way as mentioned above. 
The study revealed that the renal artery of $568 / 780$ cases $(72.8 \%)$ was a single artery and in $103 / 568$ cases, this artery showed early branches. On the other hand, the renal arteries of 212/780 cases (27.2) were multiple with left predominance. Bilateral multiple renal arteries were located in $28 / 212$ cases $(13.2 \%)$. They were double in 198 cases $(25.4 \%)$, triple in 13 cases $(1.67 \%)$ and quadruple in one case $(0.13 \%)$. The multiple renal arteries of common aortic origin were seen in 52 cases and those of similar caliber were recorded in 106 cases. The courses of the multiple arteries were either parallel to each other ( 120 cases), convergent (48 cases) or divergent ( 30 cases) towards the kidney or crossing each other (14 cases). As regard the mode of their termination, they were all hilar arteries in 156 cases, hilar and upper polar in 34 cases, hilar and lower polar in 21 cases and hilar with upper and lower polar in one case. In 29 cases of double renal arteries of different caliber, the main renal artery divided early into two branches; either both entered the hilum ( 21 cases) or one entered the hilum and the other one enter the upper pole of the kidney ( 8 cases). A coexistence of other urovascular variations on the same or opposite side, such as right renal artery passing anterior to the inferior vena cava, double renal vein, renal vein collar around aorta, polycystic kidney and aberrant inferior suprarenal artery, were also encountered.

\section{REFERENCES}

1. Ali-El-Dein, B.; Osman, Y.; Shokeir, A.; Shehab El-Dein, A. and Sheashaa, H. (2003): Multiple arteries in live donor renal transplantation: surgical aspects and outcomes. J. Urol., 169 (6): 2013-2017.

2. Alvarez-Castells, A.; Sebastia Cerqueda, C. and Quiroga Gomez, S. (2001): Computerized tomography angiography of the renal vessels. Arch. Esp. Urol., 54 (6): 603-615

3. Anderhuber, F. and Weiglein, A. (1992): The nomenclature of the blood vessels of the kidney. Ann. Anat., 174: 229-234.

4. Bakheit, M. and Motabagani, M. (2004): Anomalies of the renal, phrenic, suprarenal arteries. Saudi. Med. J., 25 (3): 376-378.

5. Benedetti, E.; Troppmann, C.; Gillingham, K.; Sutherland, D.; Payne, W.; Dunn, D.; Matas, A.; Najarian, J. and Grussner, R. (1995): Shortand long-term outcomes of kidney transplants with multiple renal arteries. Ann. Surg., 221(4): 406-416.

6. Berland, L.; Koslin, D.; Routh, W. and Keller, F. (1990): Prospective evaluation of diagnosis with color duplex US compared with angiography. Radiology, 174: 421-423. 
7. Bordei, P. and Antohe, D. (2002): Anatomical study of triple renal arteries. Morphol., 86 (274): 37-41.

8. Bordei, P.; Sapte, E. and lliescu, D. (2004): Double renal arteries originating from the aorta. Surg. Radiol. Anat., 26: 474-479.

9. Bude, R.; Forauer, A.; Caoili, E. and Nghiem, H. (2003): Is it necessary to study accessory arteries when screening the renal arteries for renovascular hypertension? Radiol., 226: 411- 416.

10. Bush, W.; Brannen, G. and Lewis, G. (1989): Ureteropelvic junction obstruction: treatment with percutaneous endopyclotomy. Radiol., 171:535538.

11. Chevrel, J. (1994): Clinical Anatomy. Le Tronc. Springer, Berlin Heidelberg, New York, 495

12. Chugh, K.; Malik, N.; Ghosh, A.; Sakhuja, V. and Minz, M. (1993): Pattern of renal arteries in normal subjects: a study of 170 renal donor angiograms. Indian J. Nephrol, 3: 9-11.

13. Debatin, J.; Sostman, H.; Knelson, M; Argabright, M. and Spritzer, C. (1993): Renal magnetic resonance angiography in the preoperative detection of supernumerary renal arteries in potential kidney donors. Invest. Radiol., 28(10): 882-889.

14. Desgrandchamps, F.; Pauthae, P.; Fornairon, S.; De Kerviller, E.; Duboust, A. and Teillae, P. (1998): Artificial ureteral replacement for ureteral necrosis after renal transplantation: report of 3 cases. J. Urol., 159: $1830-1832$

15. Evan, A.; Connors, B.; Lingeman, J.; Blomgren, P. and Willis, L. (1996): Branching patterns of the renal artery of the pig. Anat. Rec., 246 (2): $217-223$.

16. Flechner, S.; Sandler, C.; Houston, G.; Van Buren, C. and Lober, M. (1985): 100 living-related kidney donor evaluations using digital subtraction angiography, Transplantation, 40 (6): 675-678.

17. Glodny, B.; Cromme, S.; Wortler, K. and Winde, D. (2001): A possible explanation for the frequent concomitance of arterial hypertension and multiple renal arteries. Med. Hypotheses, 56 (2): 129-133.

18. Goscicka, D.; Szipinda, M. and Kochan, J. (1996): Accessory renal arteries in human fetuses. Anat. Anz., 178:559-563 
19. Gourlay, W.; Yucel, K.; Hakaim, A; O'Meara, Y.; Mesler, D. and Kerr, K. (1995): Magnetic resonance angiography in the evaluation of living-related renal donors. Transplantation, 60 (11): 1363-1366.

20. Halpern, E.; Nazarian, L. and Wechsler, R. (1999): CT and MR evaluation of accessory renal arteries and proximal renal arterial branches. Acad. Radiol., 6: 299-304

21. Khamanarong, K.; Prachaney, P.; Utraravichien, A.; Tong-Un, T. and Sripoaraya, K. (2004): Anatomy of renal arterial supply. Clin. Anat., 17 (4): 334-336.

22. Langman, J. and Sadler, T. (1996): Medical Embryology, Pradel, Paris, 301.

23. Lechevallier, E.; Bretheau, D.; Berland, Y.; Olmer, M.; Rampal, M. and Coulange,C. (1995): Outcome of kidney transplants with multiple arteries. Prog. Urol., 5 (3):370-376.

24. Lopes, J.; De Almedia, C.; Hachul, M. and Srougi, M. (1998): Frequency of stenosis of the renal artery in 676 renal transplantation. Rev. Assoc. Med. Bras., 44: 210- 213.

25. Makiyama, K.; Tanabe, K.; Ishida, H.; Tokumoto, T. and Shimmura, H. (2003): Successful renovascular reconstruction for renal allografts with multiple renal arteries. Transplantation, 75 (6): 828-832.

26. Mittal, T.; Evans, C.; Perkins, T. and Wood, A. (2001): Renal artriography using gadolinium enhanced 3D MR angiography: clinical experience with the technique, its limitations and pitfalls. Br. J. Radiol., 74: 495502.

27. Pollak, R. and Mozes, M. (1986): Anatomic abnormalities of cadaver kidneys procured for purposes of transplantation. Am. Surg., 52: 233.

28. Sampaio, F. and Passos, M. (1992): Renal arteries: anatomic study for surgical and radiological practice. Surg. Radiol. Anat., 14 (2): 113-117.

29. Satyapal, K.; Haffejee, A.; Singh, B.; Ramsaroop, L.; Robbs, J. and Kalideen, J. (2001): Additional renal arteries: incidence and Morphometry. Surg. Radiol. Anat., $23(1)$ : 33-38.

30. Shokeir, A.; El-Diasty, T.; Nabeeh, A.; Shaaban, A.; El-Kenawy, M.; Wafa, E. and Ghoneim, M. (1994): Digital subtraction angiography in potential live-kidney donors: a study of 1000 cases. Abdom. Imaging, 19 (5): 461-465. 
31. Smith, P.; Ratner, L.; Lynch, F. and Corl, F. (1998): Role of CT angiography in the preoperative evaluation for laparoscopic nephrectomy. Radiographics, 18 (3): 589-601.

32. Troppmann, C.; Wiesmann, K.; McVicar, J.; Wolfe, B. and Perez, R. (2001): Increased transplantation of kidneys with multiple renal arteries in the laparoscopic live donor nephrectomy era: surgical technique and surgical and nonsurgical donor and recipient outcomes. Arch. Surg., 136: 897907.

33. Turgut, H.; Peker, T.; Anil, A. and Karakose, M. (2001): Ureter duplication and polar renal arteries in the same case. Kaibogaku Zasshi, 76 (3): 293-296.

34. Vilhova, 1.; Kryvko, Y. and Maciejewski, R. (2001): The radioanatomical research of plural renal arteries. Folia Morphol. (Warsz), 60 (4): 337 341.

35. Vilhova, I.; Kryvko, Y. and Maciejewski, R. (2002): The frequency of different plural renal arteries rare variants. Ann. Univ. Mariae. Curie. Skiodowska (Med.), 57:68-73.

36. Volk, M; Strotzer, M. and Lenhart, M. (2000): Time-resolved contrast-enhanced MR angiography of renal artery stenosis: diagnostic accuracy and interobserver variability. Am. J. Roentgenol., 174: 15831588.

37. Volk, M.; Strotzer, M. and Lenhart, M. (2001): Renal time-resolved MR angiography: quantitative comparison of gadobenate dimeglumine and gadopentetate dimeglumine with different doses. Radiol., 220: 484- 488.

38. Williams, P.; Bnnister, L.; Berry, M.; Collins, P.; Dyson, M; Dussek, J. and Ferguson, W. (1995): Gray's anatomy, $38^{\text {th }}$ ed., Churchill livingstone, Baltimore, London, 218, 748 


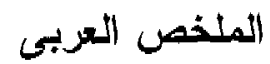

\section{تنوّعات الإمداد الشرياتي للكلية في الإسعان:}

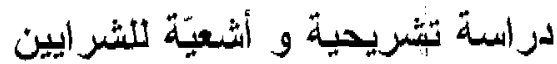

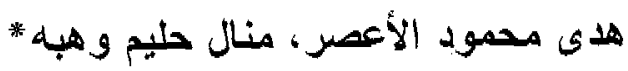

\section{قسم التشريح و قسم الأشعة *، كلية الطب، جامعة القاهرة}

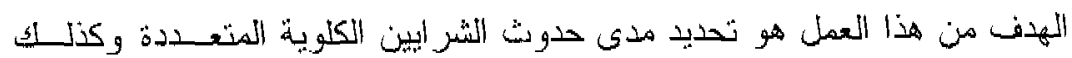

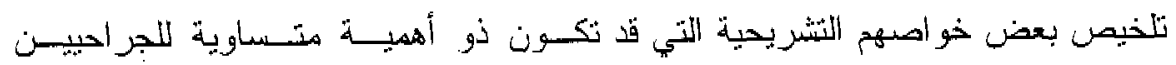
و الر اديولوجيين.

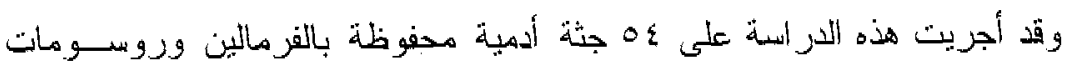

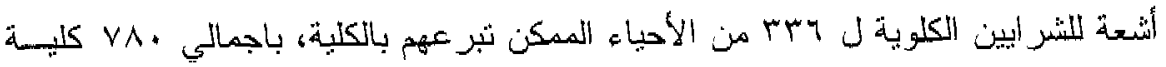

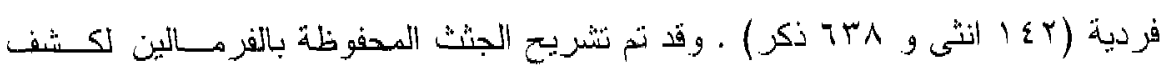

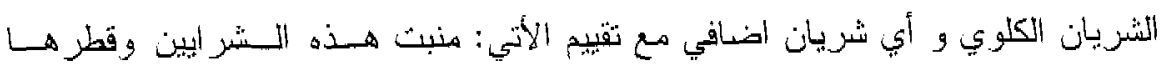

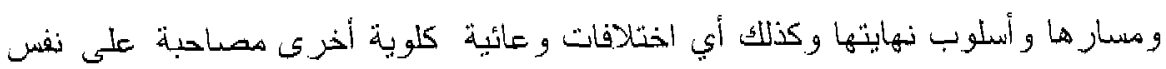

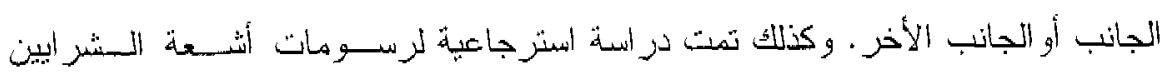

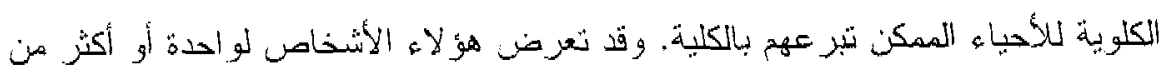

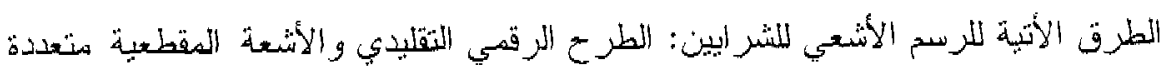

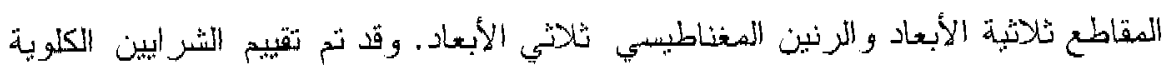

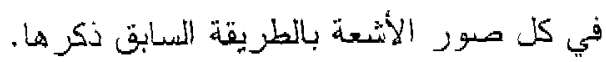

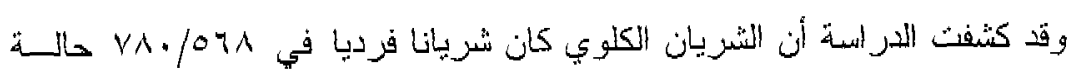

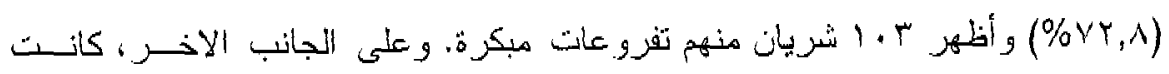

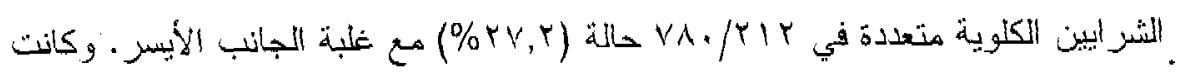

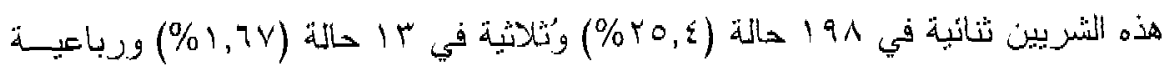

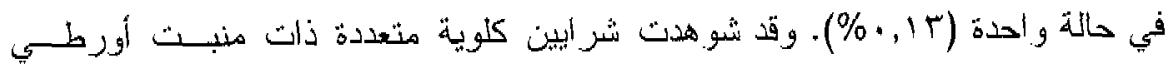

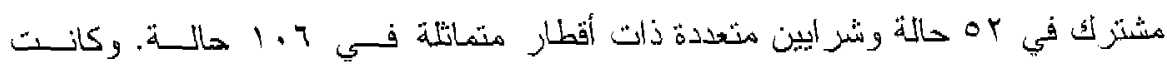

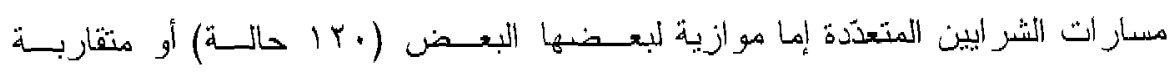




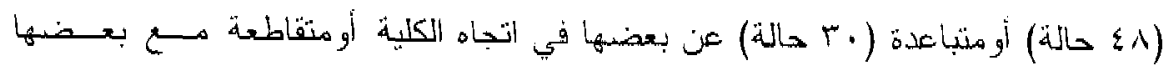

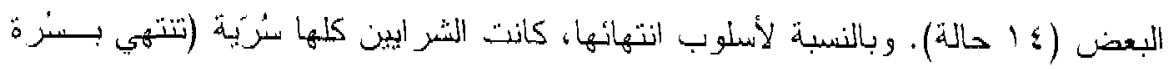

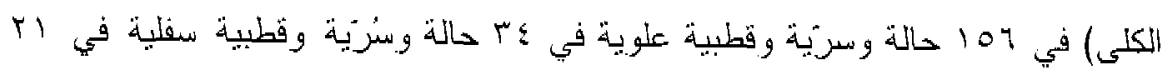

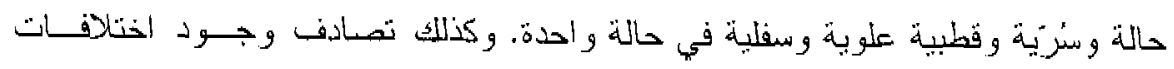

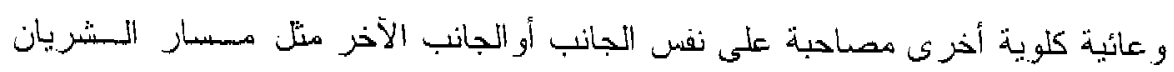

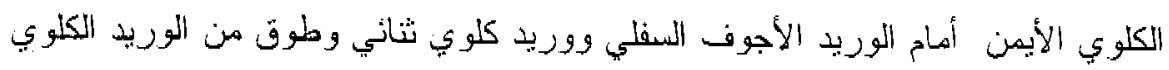

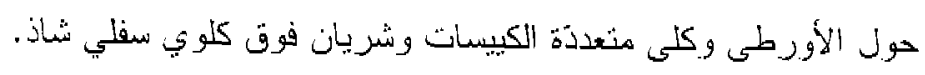

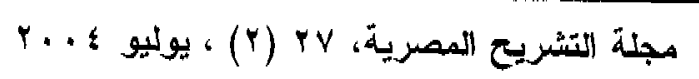

